\title{
Decisions on socialization by urban land pooling approach to renovation of landscapes of Ho Chi Minh City embankments
}

\author{
Hoang Minh Vu Nguyen ${ }^{1, *}$, A. Tuan Pham $^{1}$, L. D. Luan Nguyen ${ }^{1}$, and V. Thanh Diep ${ }^{2}$ \\ ${ }^{1}$ Urban Engineering Department, Ho Chi Minh City University of Architecture, Vietnam \\ ${ }^{2}$ The People's Committee of Tra Vinh City, Tra Vinh Province, Vietnam
}

\begin{abstract}
Land pooling and readjustment (LPR) is a significant instrument which is used to the rapid development of urbanization. It is a way of urban expansion and renovation without any compulsory revoking of land. By this way, people should not be relocated like in other ordinary planning projects, but they are encouraged to contribute their land (or land value) for construction and modernization of infrastructure system. Therefore, after contribution, remaining land will increase its value, and living conditions will also be improved. Especially, this approach is effectively implemented in urban renovation projects in various countries and regions worldwide, i.e. Japan, Germany, Korea, Taiwan, The United States of America, Australia, India, and Thailand. Its effectiveness has been demonstrated for mitigating unusual urban growth in peripheral areas. This study aims to perform the significances of LPR instrument, as well as demonstrate its practical impacts by analyzing an implemented case-study of Tra Vinh city. Recommendation of deployment is also done as a solution for renovation of landscapes of $\mathrm{Ho}$ Chi Minh City (HCMC) embankments.
\end{abstract}

\section{Introduction}

\subsection{Conceptualisation of land pooling and readjustment}

Land pooling and readjustment (LPR) is a planning technique by which small land plots are assembled into a large plot, provided with infrastructure (i.e. traffic roads, water supply and drainage system, electric and telecommunication networks, etc.), and repaired plots are returned to the landowners (see figure 1). An equal ratio of contribution land will be calculated carefully to assure that every land-owner has a same responsibility in urban and regional development. Contributed land will be re-designed in a various types of public spaces, infrastructure facilities, open spaces, and spare land plots. Spare land plots could be commercialized as kinds of luxury properties to return a partial capital cost of infrastructure construction; or to mobilize investment for construction of low-income resettlement and public facilities.

\footnotetext{
* Corresponding author: vuminh.1974@gmail.com
} 


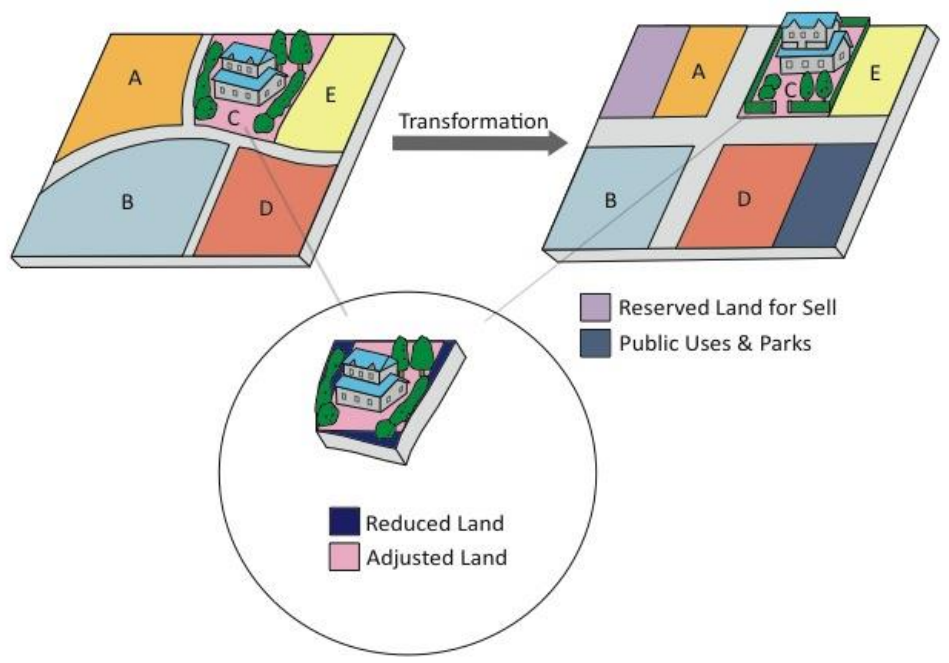

Fig. 1. Conceptualisation of Land pooling and Readjustment (LPR) [1].

The economic value of LPR is highlighted as: although reconstituted plot-areas of the land-owners will be reduced, land-value and infrastructure networks will be improved significantly in comparison with initial conditions. The increasing value, in some cases, comes from tax-policies and financial instruments. In the context of urban renovation, LPR is considered as a potential solution to orient urban space structure. In other words, LPR could be used to prevent urban development from undisciplined and random planning. Therefore, it has been implemented effectively in many urban renovation projects in various countries and regions worldwide, i.e. Japan, Germany, Korea, Taiwan, The United States of America, Australia, India, and Thailand. Especially until now, LPR is used as the primary instrument for land redevelopment in Germany. Its effectiveness has been demonstrated for mitigating unusual urban growth in peripheral areas.

\subsection{Which obstacles does LPR adapt or experiment with?}

LPR could be implemented in cases of:

1. Unbalanced interaction of supply and demand for serviced land occurs;

2. Inappropriate relation between the city development visions, master plan, urban construction plan, shapes and land-plot characteristics appears.

3. Redevelopment for inner city, disastrous regions, low-income and slum areas;

4. Assuring private rights of asset owners;

5. Lacking of public investment and/or sharing responsibilities for city landdevelopment;

6. Prevent negative impacts of land clearance, land withdrawal, resettlement, and land redistribution from habitants' awareness differences;

7. Prevent negative impacts of political purposes and social inequality on land-use.

\subsection{LPR and its advantages}

LPR advantages could be listed as:

Political feasibility: due to the fact that all the landowners will fairly share the benefits from redevelopment and infrastructure costs, LPR projects will be hastened more than other redevelopment models; 
Reduce in governmental investment cost: capital costs for renovating and constructing infrastructure systems will be shared equally between the city authorities and landowners. A partial of the investment cost could be returned by selling spare-plots after reconstitution; In other words, LPR approach could provide infrastructure investors and servicers with opportunities to recover the incurred costs;

Reduce in relocating potential: LPR is an alternative planning method in which a major part of the land will be returned to the land owners. The most important aim of this approach is the relocation of limitation to reduce resettlement cost and habitant living condition changes;

Voluntary agreement: LPR project requires strict agreements between all the land owners, public sectors, and municipal government. It means that there is less compulsoriness than other methods.

\section{Literature review on land pooling and readjustment}

LPR was initially proposed by George Washington, the first President of the United States of America, to prepare a 6,000 acres of land to build the American Capital in 1791. The Washington D.C. landowners were encouraged to contribute their land for constructing streets, public squares and buildings, open spaces, and other infrastructure facilities. Landowners who contributed their land for public buildings and open spaces (amounted to about 540 acres) were compensated at a fixed price of 25 GBP per acre [2], while land contributed for streets (account for about 3,682 acres) received no compensation. The contributed land was then reconstituted and divided into 20,272 plots, of which half were owned by the municipal authorities and the remaining land was returned to the land-owners. The agreement between the land-owners and the government was signed on March 30th 1791. The agreement effective nesses were demonstrated as: (1) land plots after being reconstituted and provided with infrastructure have become extremely valuable; (2) the city had met the needs for infrastructure and important urban facilities; (3) over 10,000 plots were set to be sold for covering capital cost of needed public buildings; and (4) it was implemented without any compulsory actions. This case-study is considered as the first effective implementation of LPR method worldwide.

Up until early 20th century, in the face of rapid urban growth and land-fragmentation in Frankfurt, the Mayor of Frankfurt-am-Main Franz Adickes proposed an important legislation of LPR to ask landowners in Frankfurt to contribute their land for public housing construction. The contributed plots were transformed to be smaller serviced land with the land-owners agreement. The municipalities were not allowed to use any expropriation to assemble private lands but they could get their need of public areas by keeping half of contributed land for city uses. The remainder was then reconstituted and redistributed back to the original land-owners for trading or private uses. This method was accepted and expanded to be deployed as primary instrument for land redevelopment in Germany during the post-war reconstruction and up till today [2].

The German LPR method was then imported to Japan for irrigation improvement projects and suburban expansion at the turn of the 20 th century. It was initially implemented in small scale mainly for agricultural land consolidation. Until the occurrence of Great Kanto Earthquake in 1923, it became a primary instrument to reconstructing large areas of downtown Tokyo and Yokohama. The Japanese Law on LPR was first released in 1954, in which comprises a great important feature that the National Government could use a partial of the Road Improvement Special Account to subsidies local government initiated projects. For this reason, LPR was become popular and has been implemented in a wide range of scales, from urban expansion to rural replotting plans, and from long-standing urban redevelopment to new urban construction, etc. According to [3] and [4], reasons of the 
widespread deployment of LPR comprise: (1) fragmentation of farmland surrounding urban fringes; (2) high prices of land; (3) not systematized management instruments of land-use; (5) conflict among parties involved; and (6) disagreement on compulsory purchases of landuse. However, the law's act still remains in force up till today.

Korean LPR concept was first introduced by the Japanese in 1934 as urban reconfiguration and farmland consolidation instrument. It has become a major tool through the enactment of the 1934 Colonial City Planning Law. The rapid urbanization of South Korea during the mid-century has put a heavy pressure on the government to assure appropriate living conditions for citizen nationwide, especially in large cities. For this reason, LPR method was deployed with the two main focuses: (1) highlight the self-financing capability of LPR projects and infrastructure servicers; and (2) promote large-scale implementation with aims to build new towns in place of master planning [1].

Then, LPR was imported to other countries around the world with various approaches and characteristics. Many countries and regions have been highlighted for their successful implementation, i.e. Thailand, India, Bhutan, Denmark, etc. LPR has been introduced to Vietnam as a pilot-scale project in Ward 7, Tra Vinh city for recent years. The project is put under supervision of the World Bank with aims to raise awareness and responsibilities of urban citizens on modernizing infrastructure system and improving urban living conditions. It is required people living in project-area to contribute their land by an appropriate ratio to renovate infrastructure system and create more land for public uses and optimize the local land-use planning. The project area is a partial of Ward 7 with approximately 24.26 hectares (see figure 2). Some agreements have been made between local authorities and the landowners, including:

- Contribution has effect on both public and private land;

- Land-owners who have contributed their land for other urban upgrading projects will not be accounted for LPR project;

- Land-owners who have small-plots will contribute as money;

- Contribution ratio is computed based on practical value of different land-types. Contribution ratio of residential land is at $13 \%$, while agricultural land has a ratio of $33 \%$.

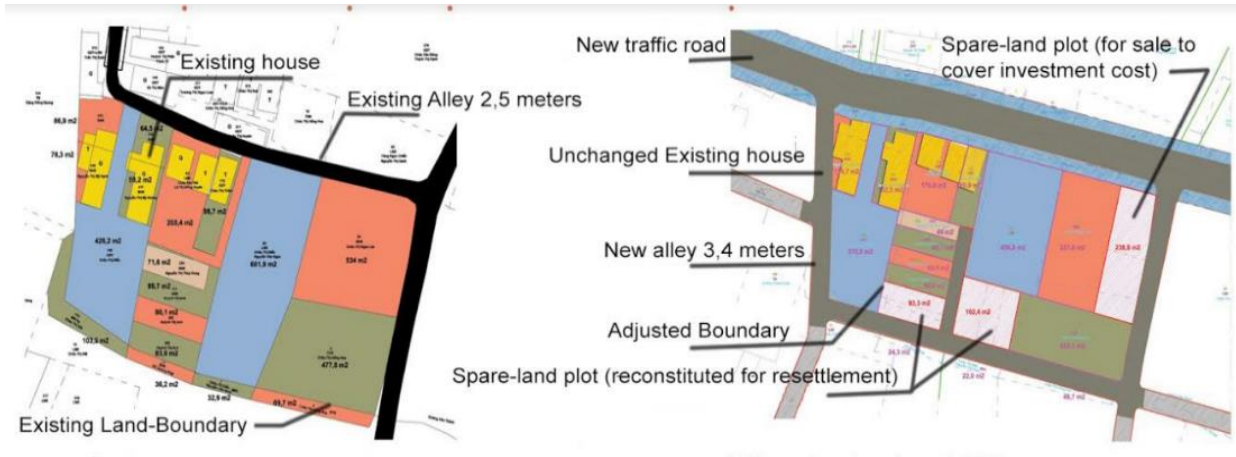

Before LPR implementation

After deploying LPR

Fig. 2. A partial of LPR pilot-scale implementation project in Ward 7, Tra Vinh city.

\section{Materials and methods}

\subsection{Materials}

As LPR method has just been introduced to Vietnam for recent years and the aims of this study is to demonstrate the feasibility of LPR solution for renovating landscapes of HCMC 
canal-sides, following materials have been obtained from various sources to be referred and cited in this study:

- Academic materials: books, journals, articles and scientific document involving LPR and its social impacts;

- Case-study reports related to LPR implementation worldwide;

- Survey data on socio-economic, infrastructure system, and living conditions of Tra Vinh city and Ho Chi Minh city;

- Expert consultants of the World Bank, local authorities, and residents in Tra Vinh city and HCMC.

\subsection{Methods}

Numerous research methods have been employed to meet the outcomes of this study, include:

- Desk study is conveyed to research on academic document and data analysis;

- Data aggregation study is used to analyze, synchronize, linearize, and restructure the primary and secondary data;

- Field research is taken to obtain practical data of construction and socio-economic data. It could be conveyed to attain experimental experience from experts;

- Empiricism study is launched for data comparison and recommendation release.

\section{LPR as socialization solutions for renovating landscapes of Ho Chi Minh City embankments}

\subsection{Land pooling and Readjustment as Socialisation Solutions}

HCMC has faced with a great rapid urbanization with fast urban growth and land fragmentation during the last two decades. According to the Decision No. 2631/QD-TTg, signed by the Prime Minister on 31 December 2013, approving the Master Plan for SocioEconomic Development in Ho Chi Minh City through 2020, with a vision to 2025, the average growth rates will be 9.5-10 percent and 8.5-9.0 percent per annum during 2016-2020 and 2021-2025, respectively. The total population is 7.94 billion in 2013. It is estimated to increase to 9.2 and 10 billion in 2020 and 2025, respectively (except nonresidents and undersix-month temporary residents). By these targets, the city is required to deal with six challenges [1]:

1. Inadequate supply of serviced land for housing development;

2. Land prices increase rapidly;

3. Difficult to find affordable housing for the poor and new migrants;

4. Squatting on public and private land;

5. Land-use could not be utilized to its potential due to the lack of tenure security;

6. The farmland preservation and food security are threaten by informal settlements.

These challenges are currently preventing the city from increasing quality of life and urbanization, especially in suburban outskirts areas. While people could not find affordable housing in the inner city, they may squat on public and private land, or build their shelters in suburban outskirts areas or alongside "garbage-canals" which have been forgotten for a long time due to its pollutions (where garbage-canal is defined as water-route which has been "wiped-out" by ineffective or indiscriminate exploitation). These situations have put the city authorities into a heavy pressure in land-use management, waterway environment protection and balancing human living conditions. This section focuses especially on land use management and LPR implementation feasibility for areas alongside the embankments, and how to renovate landscapes of garbage-canals to bring them back into viable and valuable 
areas. According to the statistics of HCMC People's Committee, HCMC waterway system consists of a dense network of canals and rivers with a total water-length of 8,000 kilometers, approximately. In order to mediate the squat of the poor to canal-sides areas and renovate the landscapes alongside the city canals, the city authorities have been conducted numerous projects and programs related to traditional housing clearance and resettlement and traditional landscape renovation. By traditional approach, the city will spend money to compensate the land-owner to consolidate the land. The land will then be re-plotted or replanned, provided with basic infrastructure system and brought to trade afterward. However, many shortcomings have been occurred due to the government financial and policy barriers. The Nhieu Loc - Thi Nghe embankment resettlement project, for example, cost more than 1,600 billion Vietnam Dong (VND) and compensated more than 7,000 relocated households. Similarly, 4,179 billion VND has been spent for relocating over 2,500 households in the U Cay channel renovation project. However, these two government-financial based projects could not meet its initial targets and could not be finished at the moment. About 10,800 canalsides households have been cleared and compensated urban wide by 2015 without any project was highlighted as successful case. In terms of reason, finance is always the biggest barrier of project. The city could not suffer adequate capital cost for all renovation projects, while national budgets would only be spent for major traffic upgrading projects. Additionally, policies and regulations on compensation, site clearance, resettlement, post-resettlement services and other relevant appeals are still not fulfilled appropriately. It leads to various obstacles related to municipal project-supervision, management, and implementation. Accordingly, only 7,500 in 15,000 households by targets were relocated during 2006-2010, while only 3,250 in 13,700 households were resettled during 2011-2015. The above statistics refer to an urgent fact that $\mathrm{HCMC}$ is required to figure-out appropriate solutions to accommodate with both finance and policy barriers. For this reason, LPR could be a new approach which is strongly believed to be an effective way to deal with the city shortcomings on land replanning and renovation. The most significant advantage of LPR associated with HCMC is the big difference between non-infrastructure and equipped-infrastructure land prices. In other words, a land-value-based instrument will play the most important role for assuring the feasibility and success of replanning and renovating projects.

\subsection{Land pooling and Readjustment in Actions, towards renovating landscapes of HCMC embankments}

In order to bring the LPR concept to practical reality of HCMC, following actions would be carried out in sequence:

1. Step 1: Convince households and stakeholders to contribute to project;

2. Step 2: Prepare local/regional land-use planning:

- Address buildable housing areas: increase land-use ratio to maximize residential land (for residential settles) and commercial land (for sales) proportions.

- Address unbuildable areas: design for canal-sides open spaces and green spaces to freshen air and improve urban aesthetics.

3. Step 3: Design for working zones and specific waterway landscapes.

Address appropriate locations for traditional open markets and modern commercial centres to attract private enterprises as well as assure income for local residents.

4. Step 4: Get agreement on relative contribution ratio.

The project could only be approved upon three conditions: (i) at least $2 / 3$ of landowners agree with the ratio; (ii) at least the owners of $2 / 3$ land area agree with the project; and (iii) disagreed landowners must be convinced that closely and compulsory consolidation could be used in cases of failure in convince.

5. Step 5: Prepare action plan and commitment. 
6. Step 6: Get agreement on planning solution and financial budget proposals of project.

7. Step 7: Project implementation under supervision of relevant stakeholders.

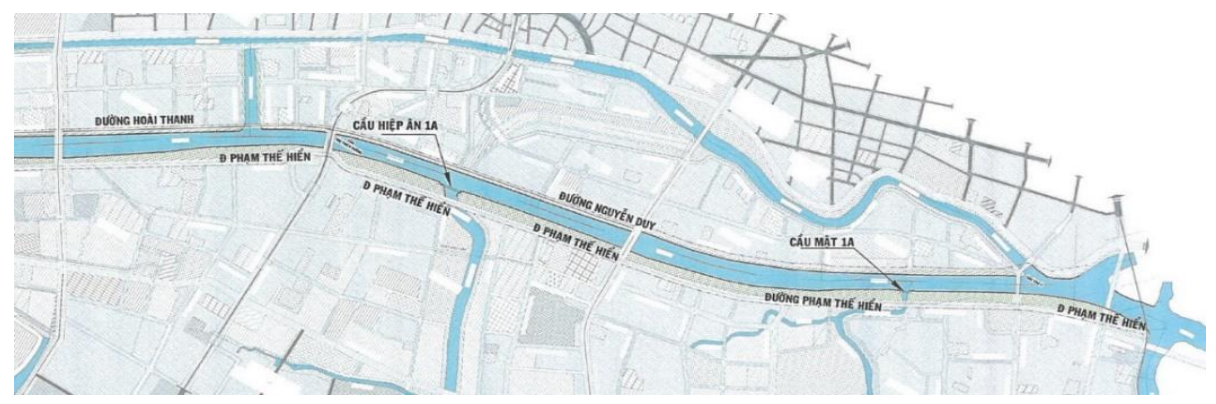

Fig. 3. Project area.

\section{Conclusions}

While the Public - Private Partners (PPP) is becoming a major co-operation method which could optimize benefits for both Government and residents by utilizing financial capacity and social management responsibility, LPR is considered as one of the most powerful approaches for land rearrangement, urban development, infrastructure upgrading, and land-value improvement. LPR has been implemented in HCMC as a flexible mechanism to mediate the financial and policy pressures for urban renovation and development programs in general and canal-sides landscape renovation in specific. It is also believed as an appropriate planning instrument to accommodate to low-budget conditions of the city. In other words, LPR is related to a sharing form of land management and land development. Its benefits, therefore, could be shared out among the stakeholders as follow:

- For the city authorities: being shared with capital cost for upgrading infrastructure facilities and social services. Also, LPR project could create more public and spare land plots to be transformed into other purposes. Additionally, infrastructure system will be upgraded sufficiently to accommodate to rapid urbanization. Regarding management issues, a fulfilled infrastructure network will make easier approaches and management for the city authorities. Therefore, maintenance afterwards would be more simple;

- For residents living in project area: their land values and living conditions will be increased significantly by fulfilled and synchronized infrastructure system;

- For project investors and infrastructure service enterprises: LPR is a flexible co-operation method which can optimize benefits for both Government and residents by utilizing financial capacity and social management responsibility. Private investors can be provided with flexible policies and conditions to maximize financial and social benefits.

\section{References}

1. The World Bank, E-learning Course on Land Readjustment - lesson 1 (Tra Vinh City, 2015)

2. URL : http://blogs.worldbank.org/sustainablecities/george-washington-and-landreadjustment (2013)

3. C. Schencking, The Great Kanto Earthquake and the Chimera of National Reconstruction in Japan (Columbia University Press, New York, 2013)

4. A. Sorensen, Planning Perspectives 16, 383-406 (2001) 